\title{
EMBRACING THE DIGITAL REVOLUTION IN THE HISTORY CLASSROOM
}

\author{
Christopher J. Young
}

Indiana University Northwest

The digital revolution provides an exciting opportunity for us to reconsider how we teach our history courses. By incorporating digital projects into our classroom repertoire, we can prepare students to do those things that we most prize as part of a liberal education and expose them to technologies that may help them develop additional skill sets. By encouraging students to engage in new learning in an environment that welcomes creativity and experimentation, we can guide our students through an empowering educational experience. A completed digital project showcases a student's critical thinking, creativity, and innovation. Projects may be shared with future employers or graduate school selection committees. In addition to contributing to knowledge that may be accessed by the public if the student wishes, a digital project may also feature those skills most desired by employers. ${ }^{1}$

Practitioners of the liberal arts, history in particular, are encouraged to look to the digital revolution as a vehicle for preparing students for success in the classroom and beyond. As Edward Ayers noted in a prescient piece on digital history, our discipline "may be better suited to digital technology than any other humanistic discipline." Historians Daniel Cohen and Roy Rosenzweig evinced the promises of digital history for practitioners of our craft, and major historical associations' dedication of

\footnotetext{
1 American Association of Colleges and Universities, "It Takes More than a Major: Employer Priorities for College Learning and Student Success: Overview and Key Findings." Retrieved from https://www.aacu.org/leap/presidentstrust/ compact/2013SurveySummary; T. Mills Kelly, Teaching History in the Digital Age (Ann Arbor: The University of Michigan Press, 2013), 85.

(c) 2018 Burke. Free to copy and share for education and scholarship under a Creative Commons Attribution NonCommercial-NoDerivatives 4.0 License.
} 
web space to digital projects and digital resources for teaching and learning underscores the need to immerse our students in the world of digital possibilities. ${ }^{2}$ This article recommends that historians continue to engage students in the scholarship of discovery but consider using digital tools to experiment with the traditional means of documenting that research.

\section{The Rationale for Using Digital Tools in the History Major}

Unlike majors residing in the professional schools, our students often have only their grades to show for their work. Hopefully they enjoyed service learning opportunities or an internship. But what if they did not have such an experience? No doubt, the individual's talents will emerge while on the job, but what about before the job offer? How do history students show the skills they acquired while studying at a college or university, especially at regional or satellite campuses of major state universities?

Frederick M. Hurst of the Personalized Learning Program at Northern Arizona University captured the problem: "If you look at someone's transcript and it says they have three three-hour courses in history, an employer doesn't know what that means other than someone knows about these time periods in history." Hurst suggests framing the history degree in a "different way" by emphasizing the "writing skills that a student got out of those

\footnotetext{
2 Edward L. Ayers, "The Pasts and Futures of Digital History," www.vcdh.virginia. edu/PastsFutures.html (Virginia Center for Digital History); Daniel J. Cohen and Roy Rosenzweig, Digital History: A Guide to Gathering, Preserving, and Presenting the Past on the Web (Philadelphia: University of Pennsylvania Press, 2006). The title of Cohen and Rosenzweig's book suggests that the direction of the literature focusing on digital work and history education comes in the form of guidebooks. Another example is Michael J. Galgano, Chris Arndt, and Raymond M. Hyser, Doing History: Research and Writing in the Digital Age (Boston: Wadsworth, 2008, 2013). For the interest that major professional historical associations have in digital history as a teaching and research tool, see American Historical Association at https://www.historians.org/teaching-and-learning/digital-historyresources and the Organization of American Historians at http://jah.oah.org/ projects/.
} 
courses" and the idea that these are skills "someone will need in the workplace." ${ }^{3}$ Digital tools allow us to move beyond the traditional means for assessing those skills or even to talk about those writing skills mentioned by Hurst. Digital tools, which are widely available and fairly inexpensive or free, provide a means for students to demonstrate mastery in contexts beyond the traditional essay. They also enable us to consider the learning needs of our students who, as T. Mills Kelly reminds us, live in a digital world "and will work in [one] tomorrow...."

History departments at colleges and universities, especially at regional and satellite campuses, are often hard pressed to find and retain history majors. There are plenty of students interested in the discipline, but competition is tough when up against professional programs. The bad publicity that liberal arts programs and degrees receive in the press and from politicians does not help. While students may be interested in a history degree, they invariably face-from themselves or from their parents-the question of marketability.

Fueling the questions regarding the worth of a history degree, or more generally, a liberal arts degree, is the very question of worth. How much is a degree worth? Was the debt incurred for a degree worth it? These types of questions are typically framed with financial value in mind rather than satisfaction. As Steven J. Tepper and Danielle J. Lindemann contend, intrinsic motivation as opposed to financial motivation leads to not only happier people, but better job performance. The "creativity and flexibility" that are prized in a liberal arts education will, they suggest, "allow the United States to compete in the global marketplace." They are not suggesting that money is not important, but if creativity is

\footnotetext{
3 Anya Kamenetz, "Are you Competent? Prove it," New York Times, October 29, 2013. Retrieved from http://www.nytimes.com/2013/11/03/education/edlife/ degrees-based-on-what-you-can-do-not-how-long-you-went.html 4 T. Mills Kelly, Teaching History in the Digital Age, 89.
} 
coupled with "money-making behaviors," students will be better prepared for "what is likely to be a turbulent future."

Moreover, as we are reminded in Sandhya Kambhampati's blog featured in The Chronicle of Higher Education, "some say using earning as a sole measure of success misses the value of a degree and how it serves society." And, as James R. Grossman, executive director of the American Historical Association, observes, there is immeasurable value to society when humanities graduates serve as teachers, clergy, and social workers. ${ }^{6}$

Yet, we in the humanities side of the liberal arts still feel an impending sense of doom, and this feeling has fueled the crisis narrative that is found regularly in higher education periodicals and is perhaps discussed amongst ourselves in history departments across the country. ${ }^{7}$ Christopher Panza and Richard Schur of Drury University likened the feeling to the famous children's story, Chicken Little, in which the drop of an acorn leads to a more general fear among the animals that the world is about to end.

\footnotetext{
5 Steven J. Tepper and Danielle J. Lindemann, "For the Money? For the Love? Reconsidering the 'Worth' of a College Major," Change 46 (2014):
} 20-23.

6 Sandhya Kambhampati, "Measuring Humanities Degrees Misses Much of Their Value," The Chronicle of Higher Education. Retrieved from http://chronicle.com/ blogs/data/2014/10/20/measuring-humanities-degrees-misses-much-of-theirvaluel

7 Paul B. Sturtevant, "History is Not a Useless Major: Fighting Myths with Data," Perspectives on History 55 (April 2017), https://www.historians.org/ publications-and-directories/perspectives-on-history/april-2017/history-isnot-a-useless-major-fighting-myths-with-data; Julia Brookins, "Survey Finds Fewer Students Enrolling in College History Courses," Perspectives on History 54 (September 2016), https://www.historians.org/publications-and-directories/ perspectives-on-history/september-2016/survey-finds-fewer-students-enrollingin-college-history-courses; Julia Brookins, "The Decline in History Majors: What is to be Done?" Perspectives on History 54 (May 2016), https://www. historians.org/publications-and-directories/perspectives-on-history/may-2016/ the-decline-in-history-majors; Christopher Brooks, "Connecting the Dots: Why a History Degree is Useful in the Business World," Perspectives on History 53 (February 2015), https://www.historians.org/publications-and-directories/ perspectives-on-history/february-2015/connecting-the-dots. 
They seek refuge in the cave of a fox, where they are ultimately devoured. While Panza and Schur persuasively make the case that much of the concern in the humanities is overstated, they do agree that the humanities have a public relations problem.

They suggest that the narrative needs to change in order to modify the way humanistic disciplines are perceived by the wider public. To be sure, the authors do not discount the very real possibility that every article questioning the worth of a degree in the humanities may be understood as a "potential falling acorn." Nor do they downplay that "false crisis narratives have real effects."

I think the crisis narrative can turn us into better teachers by forcing us to reconsider how we prepare our history majors for the world they are likely to encounter. The perceived crisis should be seen as an opportunity to take a risk and pursue innovative approaches in the classroom.

This perceived crisis was on my mind when I first encountered the quote above by Frederick Hurst. I had witnessed many instances of creativity, even brilliant creativity from my students. Until reading Hurst's words, these moments of creativity were, for me, interior building blocks that built the intellectual character of the student and eventual employee. I hoped that their experience with a class project that encouraged creativity would in some small way contribute to their life's enrichment while contributing to their skill set. And while all this may be true, it is difficult to get beyond the idea that a prospective employer will only see that they took a three credit hour course on the American Revolution.

To distill the problem to its most basic question is to ask: How do we demonstrate a history student's value to prospective employers? How do we provide for "tangible evidence of learning" and showcase "critical and creative thinking" while documenting that students are equipped with "digital fluency and information literacy"-critical skills in the twenty-first century workplace as

8 Christopher Panza, and Richard Schur, "To Save the Humanities, Change the Narrative," The Chronicle of Higher Education” 61 (2014): A64. 
well as in contemporary society? ${ }^{9}$ To make digital literacy a course objective, it behooves us, as Jeff McClurken explains, to encourage students to "experiment with a variety of online tools, and then to think critically and strategically about a project, and to identify those tools that would be most useful to that project." 10

\section{Providing Opportunities for Digital Experimentation}

Inspired, I decided to design a project that would enable my students to provide tangible evidence of learning that could "demonstrate a [humanities] student's value to prospective employers." The answer was to digitize the classroom experience and to thereby explore a variety of digital possibilities in different learning environments. I am not claiming to be the first to have had this insight or that my approach is the most innovative. In fact, some readers may think I am years behind in uncovering the digital experience. And I may very well be. However, I suspect I am not alone in my desire to find new and interesting approaches to courses that I have taught for some time and that enroll students who will face different challenges than an earlier generation and who will be expected to have a different skill-set.

To those who are neither technologically inclined nor comfortable with technology, there is some risk involved when digitizing the classroom experience. However, that characteristic proves to be an asset because one's own risk-taking with a new enterprise will encourage students to take their own risks as long as they are given the opportunity to do so creatively and without significant consequences.

With this in mind, I designed a 200-level seminar course (required of history majors) with three goals that are fairly standard for my classes. Students would: learn course content

\footnotetext{
9 Anya Kamenetz, "Are you Competent? Prove it."

10 Jeff McClurken, "Digital Literacy and the Undergraduate Curriculum," in Hacking the Academy: New Approaches to Scholarship and Teaching from Digital Humanities, eds. Daniel J. Cohen and Tom Scheinfeldt (Ann Arbor: University of Michigan Press, 2013), 80-81.
} 
while acquiring a skill that they are likely to use in their working lives; be encouraged to take risks and to be creative; stretch and grow as individuals.

The subject of the course in which I first attempted to use these digital tools was public memory. Digitizing the learning experience in this course played out in a variety of assignments, a number of which could be used to reinforce or build on one another. These assignments included digital timelines, annotating an eighteenth-century play as a group with GoogleDocs, analyzing a topic using the Google Ngram Viewer, and a final digital project that would have a public audience. Essentially, each student was required to produce a final research project and present it using a web based tool while also incorporating, when appropriate, digital tools that were the basis of other class assignments, such as the Google Ngram Viewer. Within the broad topic of public memory, students could choose any point of focus that interested them. Topics ranged from Korean War memorials in the United States, to the intersection of popular culture, public memory, and the American space program, to the use of video games as a vehicle for public memory. A well-executed final product would be soundly argued, thoughtfully analyzed, and creatively presented or displayed. I invited the students who created the best work to present their final project at our campus's annual College of Arts and Sciences Conference. ${ }^{11}$

11 The play was Robert Munford's The Candidates. The Revolutionary Era play was published posthumously in 1798. Robert Munford, A Collection of Plays and Poems (Petersburg, VA: Williams Prentis, 1798). 


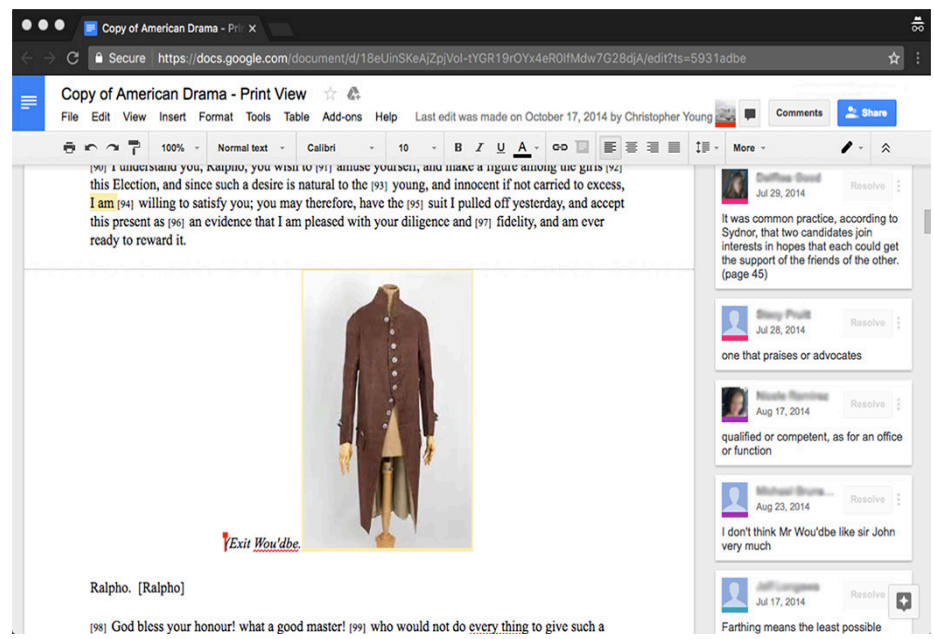

Figure 1: Google Docs allowed students to annotate an eighteenth-century play together.

My hope was that should students decide to keep their digital work, they would have tangible evidence of learning. The finished product could stand on its own or be incorporated into an e-portfolio.

Taking on the digital project meant experimenting with different tools. Some worked out better than others. WordPress, a blog site that has increasingly been used for its website development capabilities, proved to be cumbersome for a number of students. Another digital tool that students used, and later embedded in their final work, was the Google Books Ngram Viewer. This fun and useful tool graphs the use of specific words or phrases in the Google-scanned books and periodicals published between 1500 and 2008. The assignment was to analyze the results, and if pertinent, to incorporate their Ngram analysis into their semester project in order to illustrate a point or support their argument. ${ }^{12}$

12 John R. McNeill, "Lessons of Munich, Lessons of Vietnam, Lessons of History," Perspectives on History 51 (September 2013): 9-11; Christopher J. Young, "From Mr. Lincoln to Abraham Lincoln, from the Personal to the Historical: Google's Ngram Viewer as a Research Tool," For the People: A Newsletter of the Abraham 
Both the students and I found Tumblr, a blog site with a social media feel, more user-friendly than WordPress. A key to its success, I believe, was that two students recommended using it. Their endorsement, I suspect, helped their peers feel comfortable with the medium even though it remained a new and challenging experience for some. Other instructors who have allowed students "to determine their media choice" have found that it "builds trust and relationships"-and my experience would confirm this observation. ${ }^{13}$

In my upper division Colonial and Revolutionary American course, students used Tumblr to take the three required exams. To get started, we built a site together so students could get comfortable with the platform. Modeling of this sort is an effective approach to introducing students to new methodologies and learning technologies because it provides opportunity for "feedback and support for those students who might not have a vision for the end product." ${ }^{14}$ Using Tumblr for the exam invited students to produce creative and beautiful work that included an analysis of major themes and key points on the course's three areas of focus: Colonial America, Revolutionary America, and the Memory of the American Revolution. They enjoyed bringing their own creative twists to each exam. And, the images, graphs, and videos that were included made for a much more interesting and satisfying grading experience. The reason, I believe, is that the students were not so much taking an exam, as they were "making history" as described by T. Mills Kelly in his masterful work, Teaching History in the Digital Age. ${ }^{15}$

Lincoln Association 17 (2015): 6-8.

13 Denise Castro, "Blog Attack: New Teaching Strategies to Engage Today's College Students," Metropolitan Universities: An International Forum 23 (September 2012): 86.

14 Ibid., 94.

15 Kelly, Teaching History in the Digital Age, 78-101. 


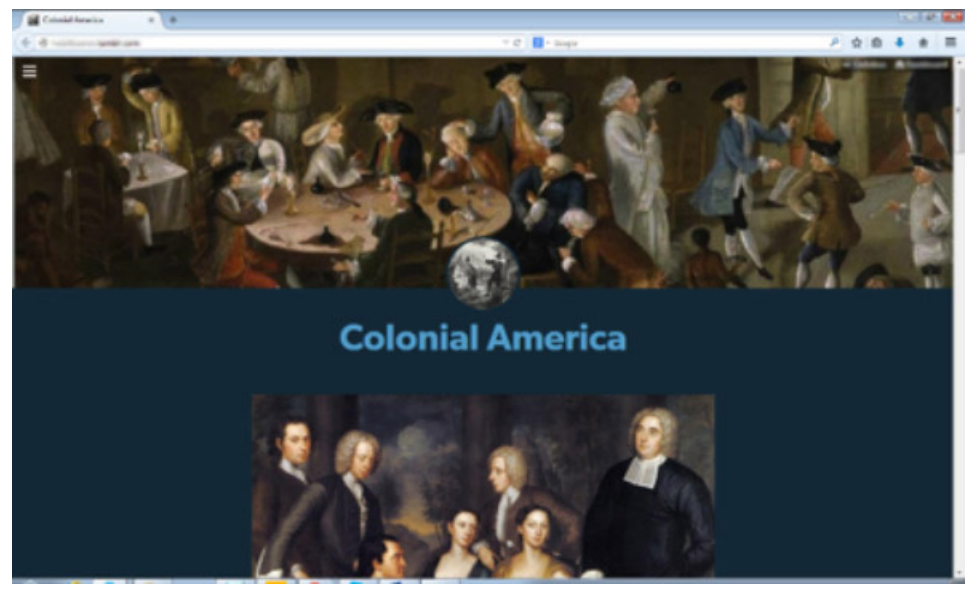

Figure 2: The opening view of a student's exam on Tumblr. The digital tool encourages students to take a colorful approach to the traditional exam.

The use of Tumblr has been a general success. As with introducing the other learning technologies, students experienced anxiety at first with Tumblr before embracing it. As I did earlier with WordPress, I encouraged students to think of the site as an opportunity to showcase their work following the course. It is also an opportunity to remind students to remove the sites or make them non-public if they do not wish others to see their work in the future while also raising their awareness of mixing the personal with the professional on such publically accessible sites.

Tumblr or other website development sites serve the purpose of showcasing students' work well if one's institution does not support software for a coordinated e-portfolio effort. Students reported that Tumblr was easy to use and that it provided a "unique" and "interesting learning experience." One student said that using Tumblr allowed for posting images, which added "some visual context." This, the student noted, brought "depth" to the learning experience. Another student noted that submitting essay exams through Tumblr "facilitated learning because it made us truly understand the material and add our own flavor to it." While I wish I could have followed up with the students to learn precisely 
what they meant by these comments, they all suggest nonetheless that students felt they had a meaningful learning experience.

Additionally, inspired by Carol A. Davis's use of "autonomy" in the classroom, I asked students in one of my 300-level courses to volunteer to build maps. A number of students accepted the opportunity, but only two completed the task. They each tried to map an instance described in David Hackett Fischer's Paul Revere's Ride. ${ }^{16}$

One student used Google maps while the other used MapBox. One of these students remarked on the learning experience by acknowledging how the assignment had brought an awareness of the changing landscape between today and the eighteenth century. She shared with me that when she was "recreating the map, I was getting confused with the land masses. Little islands from the map in the book were either completely gone or have moved significantly. Also, I thought it was really interesting how, over the years, land was filled in or changed (such as BostonLogan airport's location). From a geographical standpoint, I definitely learned a lot about how the land changing coincided with economic issues." Digital mapping provides an opportunity to demonstrate to students that a nation's narrative "is influenced by its own deep history and geography." ${ }^{17}$

Using Qualtrics software, I asked students to complete a Human Subjects Committee-approved survey at the beginning of the course and at the conclusion of the course. When asked if digital research had ever been part of an assignment in any of their classes, half of the class responded in the affirmative and the other half responded in the negative. When questioned if web-based applications had ever been the basis of a class assignment such as

16 Carol A. Davis, "Game Theory and Reality TV: Pathways to Democratic Thinking," Diversity \& Democracy 17 (2014): 28; David Hackett Fischer, Paul Revere's Ride (New York: Oxford University Press, 1995).

17 Robert D. Kaplan, The Revenge of Geography: What the Map Tells Us About Coming Conflicts and the Battle Against Fate (New York: Random House, 2012), $\mathrm{xx}$. 
a term paper, the entire class answered no. When queried if they found the digital project assignment worthwhile, the response was unanimously affirmative. Overall, the surveys suggest that digital assignments introduced students to new educational experiences that contributed to a meaningful learning experience, such as "figuring out what exactly constitutes public memory and how it is formed."

When asked to explain their answers regarding their learning experiences, one of the students in the 200-level seminar wrote, "I think the digital project challenged students to take on a technology and way of doing things that was unfamiliar and unusual, but highly useful. Being able to write and publish for an internet-driven age will be a valuable skill going forward." For another student, not only did the digital project rejuvenate one's enthusiasm for research "due to the atypical format in which the final product is showcased," but, the student commented, as someone "who will be in the job market in the near future, having to do research and present findings in a manner other than a formal paper helps mature writing techniques that quite possibly could be crucial in careers other than academia (and even in academia)." For this student, the project emphasized "a different way of writing, communicating, and learning new skill sets that are often overlooked in research papers." Another student commented that the digital project is much more "flexible than your standard research paper, with a number of different options to enhance and change the way the paper is received by the reader. I don't think that it is better than a traditional research paper, but it will likely add valuable new skills and challenge the way most students think of a research project."

When I surveyed other lower and upper division classes in which I used digital tools and methods, the student-responses were similar. Most had conducted digital research as part of an assignment, but web-based applications such as Tumblr, WordPress, Google Docs, and Google Books Ngram Reader, and 
Dipity were almost never the basis of the assignment. And nearly all students felt that the digital project was beneficial to their learning experience.

While the digital path presents some disadvantages, these prospective realities would be better described as potential disadvantages than actual disadvantages. Instructors who go digital need to avoid throwing "the baby out with the bathwater" by introducing so many digital tools that the learning curve with the new learning technologies dominates the learning experience rather than the course subject itself. Another potential problem, and one I experienced, is that by taking such a radical approach, one may feel unmoored. Those who have been teaching for a while have a sense of how a course is going at certain points during the semester. For instance, when I went digital, I gave up familiar pedagogical landmarks such as traditional writing assignments and exams by which I could judge the progress of the course and my students, the absence of which made me anxious regarding the course's success and the students' experience in it. The solution to this problem is to incorporate digital projects gradually or to establish clear markers early and often so one feels anchored.

One last potential disadvantage, which is related to the first, is whether something is lost when digital tools and projects are made a regular part of the learning experience. Does something have to give when we transform the way we conduct our business? It is a balancing act, to be sure, but it is one that may take time to achieve, just as it took time and mistakes for us to establish a pedagogical approach that we found worthwhile, effective, and enjoyable before the digital revolution.

Conversely, there are some clear advantages to using digital tools in the history classroom. While students may experience trepidation when first given the assignment, it is likely that eventually they will find it exciting to approach the familiar term paper or exam in an innovative way. It is this type of creativity and experimentation with digital tools, Paula Krebs reminds 
us, that will prepare our students in community colleges and comprehensive regional universities to contribute to the economic well-being of the immediate area being served by the academic institution. Additionally, students get "more bang for the buck" since they will learn not only content, but also a new skill and gain a new-found confidence that may prove to be a useful as they embark on their careers. ${ }^{18}$

Embracing the digital revolution has expanded my understanding of student learning. I have learned that students appreciate and enjoy having the opportunity to be creative. They are willing to take risks and try new things in an academic environment if they know they will not be penalized for doing so. And students like that digital tools and projects and the nontraditional approaches they encourage "provide room to learn," as a student recently told me as we exited a classroom.

By digitizing the learning experience, we are preparing history students in a classical sense by having them engage in the scholarship of discovery, but we are also giving them a real sense that they are contributing to knowledge by publishing via Tumblr or WordPress. This opportunity provides a medium through which students may showcase their digital fluency and information literacy to prospective employers or graduate school selection committees.

18 Paula Krebs, "Will it Play in Emporia," Slate (April 2014). Retrieved from http://www.slate.com/articles/technology/future tense/2014/04/don t forget regional state schools when it comes to higher ed and tech.html. In one of my classes, I had a non-traditional student who was particularly hostile to the introduction of digital tools into the classroom. The assignment was to annotate an eighteenth-century play together using GoogleDocs. After expressing her displeasure on several occasions, her attitude toward the subject suddenly changed over the course of the weekend. She confided to me that while complaining about the assignment to one of her friends, her friend said, "GoogleDocs? We use that all of the time at work." Knowing that she would be using this digital tool as an employee gave the assignment value. 
The students-as prospective employees or graduate studentswill be more than the grade on their transcript. Their talents, their skills, and their creative impulses will provide the story behind the grade. We like to think that the transformative potential of a liberal arts degree is more than a class, a grade, or a transcript. It is to be discovered in the people who experience it. The digital revolution provides opportunities for students to showcase their discoveries, and though them, to highlight students' growth and potential far beyond the classroom. 